\title{
Demographics Domain
}

National Cancer Institute

\section{Source}

National Cancer Institute. Demographics Domain. NCI Thesaurus. Code C49572.

A subject domain utilized for the submission of information encompassing and representing data, vocabulary or records related to demographics. 